\title{
Aberrant "Barbed-Wire" Nuclear Projections of Neutrophils in Trisomy 18 (Edwards Syndrome)
}

\author{
Basil M. Kahwash, ${ }^{1}$ Nicholas B. Nowacki, ${ }^{2}$ and Samir B. Kahwash ${ }^{3}$ \\ ${ }^{1}$ Department of Medicine, University of Indiana, Indianapolis, IN 46202, USA \\ ${ }^{2}$ Department of Pathology, The Ohio State University Wexner Medical Center, Columbus, OH 43210, USA \\ ${ }^{3}$ Department of Pathology and Laboratory Medicine, Nationwide Children's Hospital, Columbus, OH 43205, USA
}

Correspondence should be addressed to Samir B. Kahwash; samir.kahwash@nationwidechildrens.org

Received 13 October 2015; Accepted 25 November 2015

Academic Editor: Stephen Langabeer

Copyright (C) 2015 Basil M. Kahwash et al. This is an open access article distributed under the Creative Commons Attribution License, which permits unrestricted use, distribution, and reproduction in any medium, provided the original work is properly cited.

We discuss the significance of neutrophils with increased, aberrant nuclear projections mimicking "barbed-wire" in a newborn child with trisomy 18 (T18). Increased, aberrant nuclear projections have been previously reported in trisomy of the D group of chromosomes (chromosomes 13,14, and 15), and we report similar findings in a patient with T18. The peripheral blood smear showed relative neutrophilia with the majority (37\%) of neutrophils showing two or more thin, rod-shaped or spike-shaped, and often pedunculated aberrant nuclear projections. The number of projections ranged from 2 to 6 per cell, averaged 2 per affected neutrophil, and ranged in length from $0.22 \mu \mathrm{m}$ to $0.83 \mu \mathrm{m}$. This case confirms that the morphologic finding described is not restricted to trisomy of one of the chromosomes in group D, as implied in the literature.

\section{Introduction}

Trisomy 18 (T18), also known as Edwards syndrome, typically occurs as a result of nondisjunction during meiosis and is the second most common live-born autosomal trisomy. The overall prevalence is estimated at $1 / 2,500-1 / 2,600$, and the live-born prevalence is estimated between $1 / 6,000$ and $1 / 8,000[1,2]$. The syndrome is characterized by cardiac septal defects, patent ductus arteriosus, horseshoe kidneys, dysgenesis of the central nervous system, characteristic craniofacial abnormalities, and overlapping or overriding fingers, among other features. About half of live births with T18 survive past the first week of life, and an estimated 5-10\% live beyond one year of life [1]. Kagan et al. [3] compared 56,000 healthy infants to 395 infants with trisomy and showed that an algorithm of maternal age, prenatal maternal serum markers, and prenatal ultrasound screens is extremely sensitive for T18 (97\% detection rate), with few false positives (3.1\%).

Single, and often round and bulbous, nuclear appendages of neutrophils are commonly seen in healthy females. First described in 1949 by Barr and Bertram [4] in the motor neurons of female cats and later coined "Barr bodies," these appendages were proven to be inactivated $\mathrm{X}$ chromosomes [5]. Davidson and Smith [6] showed that Barr bodies appeared as "dumbbell-" shaped nuclear appendages of neutrophils, and their presence strongly correlated with the female sex. Historically, the absence of Barr bodies in oropharyngeal epithelial cells of female buccal smears suggested Turner syndrome [7] and the presence of Barr bodies in male skin keratinocytes suggested Klinefelter syndrome [8]; however, these methods are now considered obsolete.

Increased abnormal nuclear projections were first associated with trisomy of the D group of chromosomes 13, 14, and 15 by Huehns et al. in 1964 [9]. Huehns described six children, each with trisomy of one of the chromosomes in the D group, with the majority of neutrophils showing multiple (ranging between 1 and 6) abnormal nuclear projections described as extremely variable in size and shape. Subsequent electronmicroscopic studies confirmed that these projections were indeed nuclear, as they consisted of nucleoplasm often 


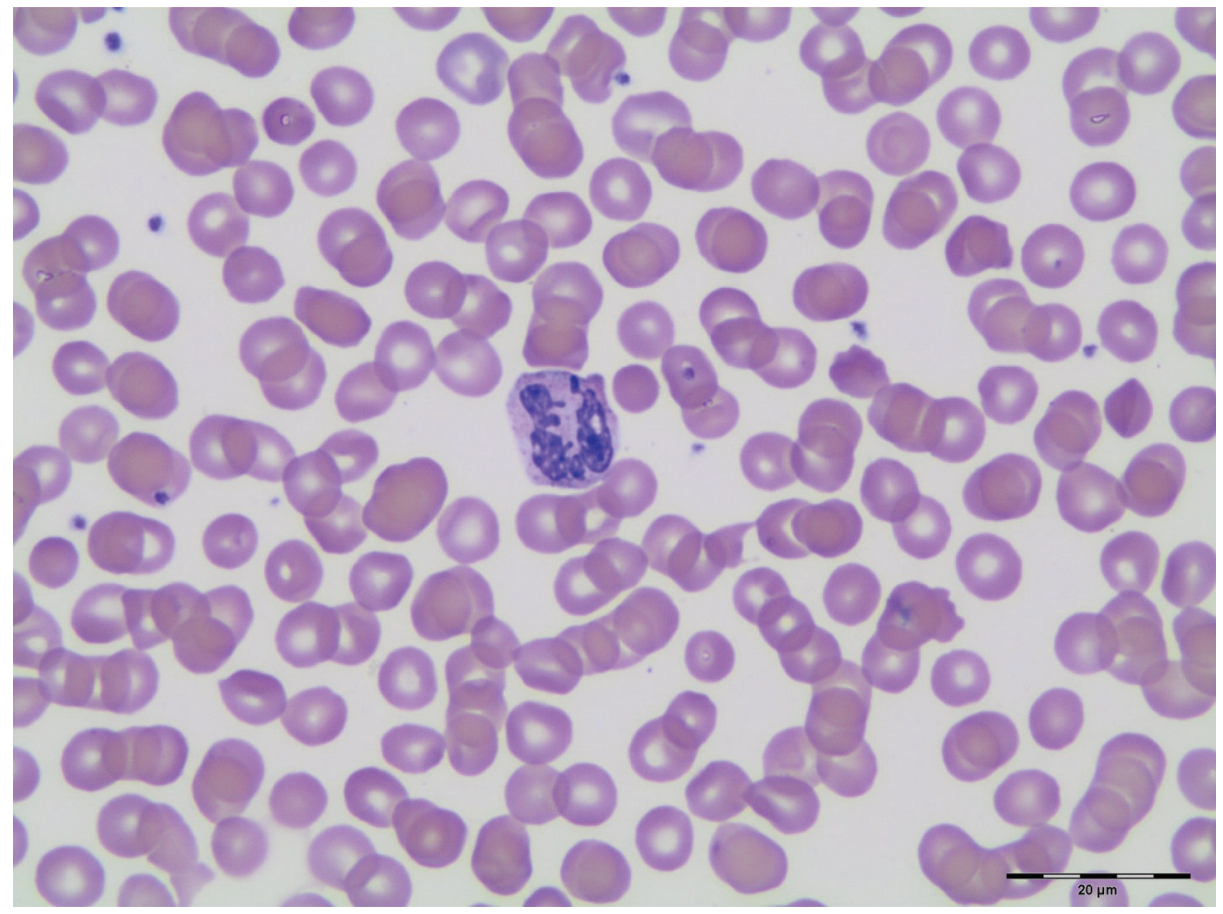

FIGURE 1: A neutrophil with aberrant thin, rod-shaped, spike-shaped, and pedunculated nuclear projections (Wright Giemsa stain, 100x oil).

forming long stalks with terminal swellings [9, 10]; however, their exact etiology remains unclear.

\section{Case Report}

A premature, 33-week gestational age, female was noted to be cyanotic at birth and in respiratory distress. Upon further evaluation, she was also found to have multiple congenital abnormalities including bronchopulmonary dysplasia, dextrocardia, ventricular septal defect, patent ductus arteriosus, and agenesis of corpus callosum. Prenatal screening suggested T18, and it was confirmed by subsequent karyotype analysis, specifically $47, \mathrm{XX},+18$ (10 cells counted). The patient was transferred to our tertiary care hospital at 1 month of age due to worsening respiratory function. Her initial complete blood count (CBC) showed normocytic anemia (hemoglobin $7.1 \mathrm{~g} / \mathrm{dL})$, an adequate platelet count $(266 \times$ $\left.10^{9} / \mathrm{L}\right)$, and a normal leukocyte count $\left(8.3 \times 10^{9} / \mathrm{L}\right)$. The patient was transfused with packed red blood cells and given all needed supportive measures. A follow-up CBC showed hemoglobin of $11.7 \mathrm{~g} / \mathrm{dL}$, a platelet count of $\left(178 \times 10^{9} / \mathrm{L}\right)$, and leukocyte count $\left(11.3 \times 10^{9} / \mathrm{L}\right)$. Review of the peripheral blood smear showed a normal differential cell count with $37 \%$ of neutrophils showing two or more thin, rod- or spike-shaped, and slightly pedunculated, aberrant nuclear projections (Figures 1 and 2) mimicking the appearance of "barbed-wire." The number of projections ranged from 1 to 6 per neutrophil, averaged 2 per cell, and ranged in length from $0.22 \mu \mathrm{m}$ to $0.83 \mu \mathrm{m}$.

The patient's hospital stay was significant for worsening complex medical problems and deteriorating respiratory function, sadly leading to death at 3 months of age.

\section{Discussion}

We believe that this is the first report of increased and aberrant nuclear projections in a T18 patient. Aberrant nuclear projections were first described in patients with trisomy of the D group of chromosomes 13, 14, and 15 in 1964 by Huehns et al. [9]. Later, Walzer et al. [11], comparing 11 patients with group $\mathrm{D}$ trisomy to 74 controls, suggested that $>15 \%$ of neutrophils with two or more projections is highly suggestive of a group D trisomy. Others [10, 12, 13] reported similar findings, including one case with trisomy 14 mosaicism [14] and a single report [10] of similar findings in a patient with partial group $C$ (chromosomes 6-12) trisomy. Across all reports, the projections were described similarly in appearance (Table 1), with a range in size of $0.25 \mu \mathrm{m}$ to $1.5 \mu \mathrm{m}$ (with Barr bodies measuring an average of $1.5 \mu \mathrm{m}$ ). Aberrant nuclear projections of the "barbed-wire" type can be easily distinguished morphologically from Barr bodies. The latter tend to be single and relatively thick and show a rounded dumbbell shape with a tendency to project inwards within the nuclear curve of a neutrophil (Figure 3 ). We also note a single study [15] which showed similar increased aberrant nuclear neutrophilic projections in patients receiving glucocorticoids and androgen therapy.

Our case shows aberrant nuclear projections mimicking "barbed-wire" in a newborn with T18 and confirms that this morphologic finding is not restricted to trisomy of the group $\mathrm{D} / \mathrm{C}$ chromosomes, as previously suggested in the literature [9-14]. Maternal screening has been shown to be effective, but not perfect, in prenatal detection of T18 and may not be available in all parts of the world. Swift interpretation, within one hour, of the peripheral blood smear by pathologists could 

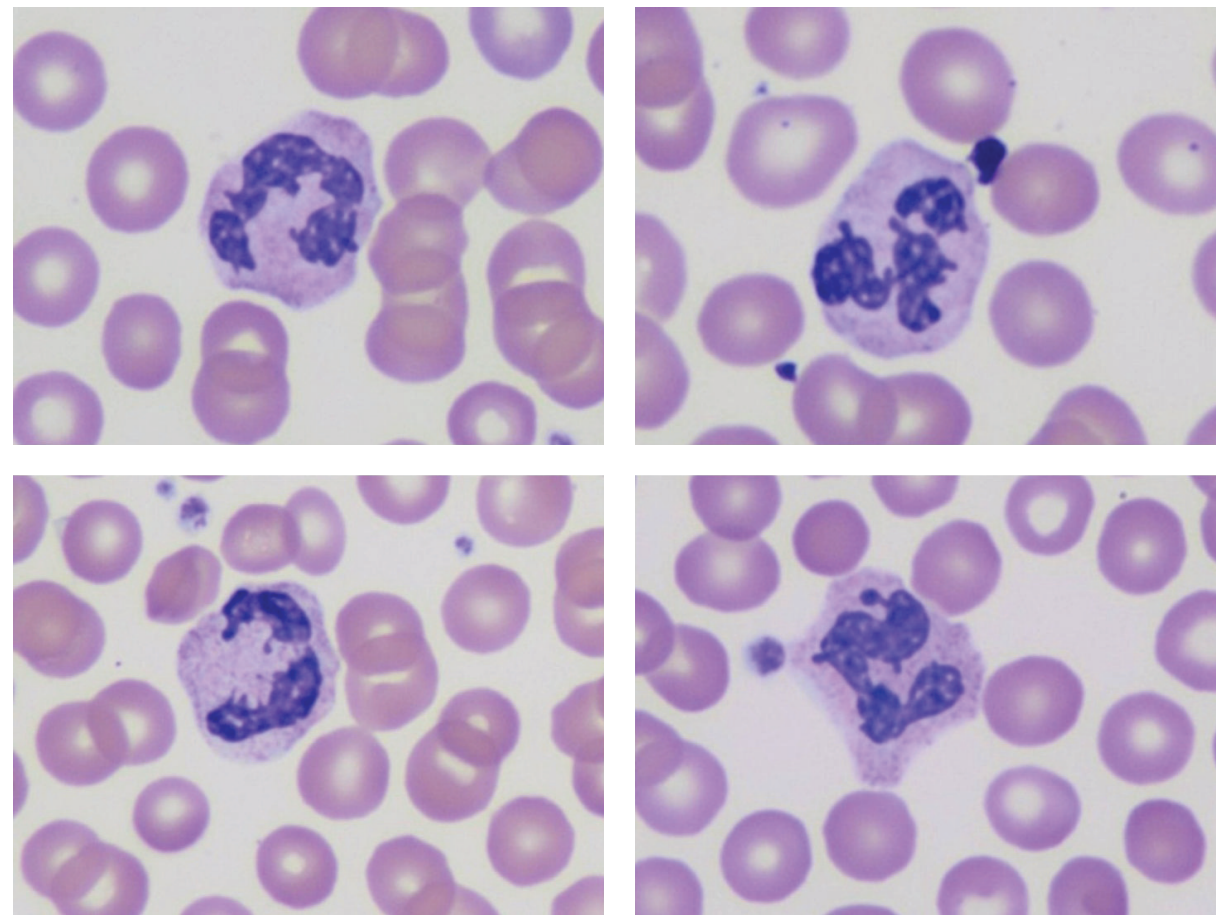

Figure 2: Additional neutrophils with "barbed-wire” aberrant nuclear projections (Wright Giemsa stain).

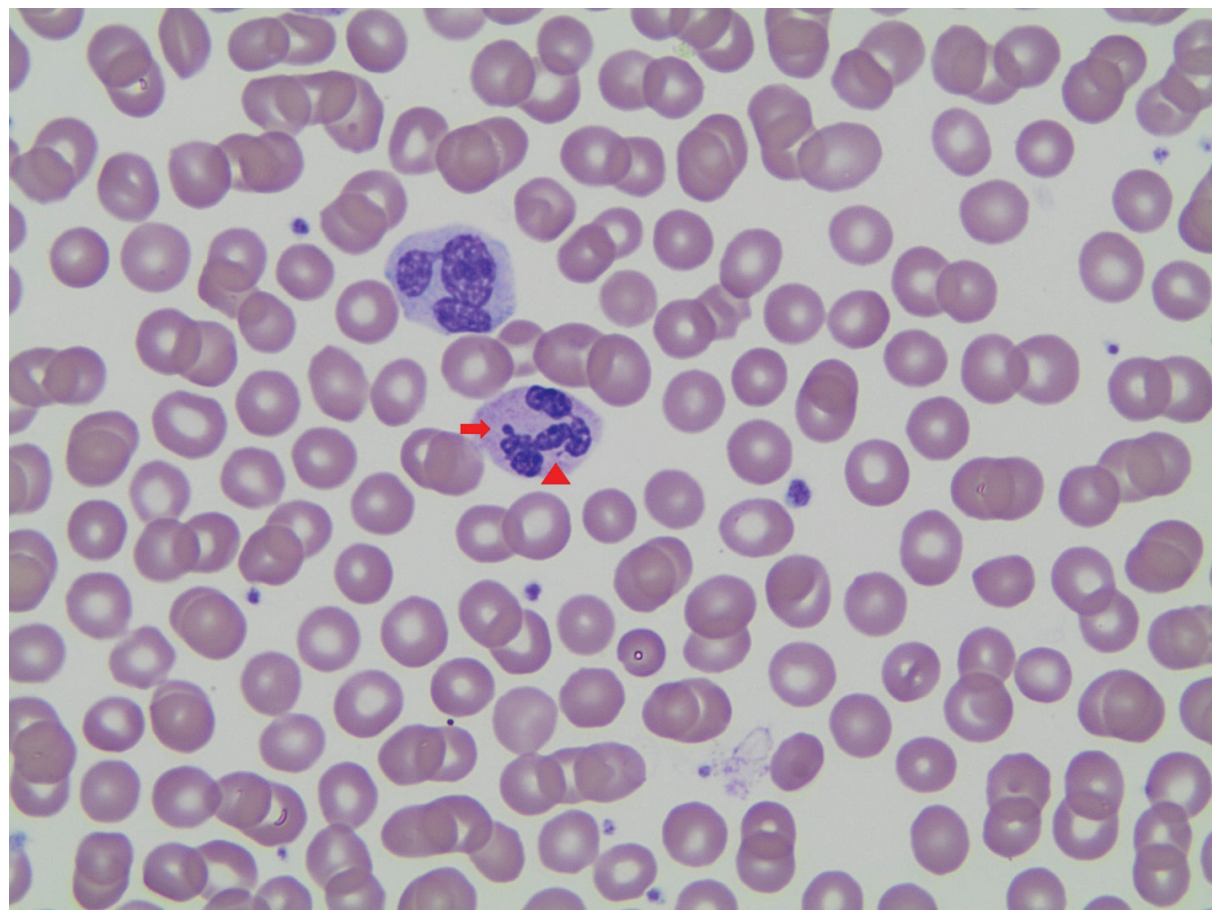

FIGURE 3: A neutrophil showing one Barr body (arrow) and one "barbed-wire" type aberrant nuclear projection (arrow head) (Wright Giemsa stain, 100x oil). 
TABLE 1: Summary of case information in articles describing aberrant nuclear projections associated with chromosomal trisomies.

\begin{tabular}{|c|c|c|c|c|c|c|}
\hline \multirow{2}{*}{ Report (year) } & \multirow{2}{*}{ Number of cases } & \multirow{2}{*}{$\begin{array}{l}\text { Trisomy } \\
\text { chromosome }\end{array}$} & \multicolumn{4}{|c|}{ Nuclear projections } \\
\hline & & & Description & \# per cell & Size & $\%$ of neutrophils \\
\hline Huehns et al. (1964) [9] & 6 & D group & $\begin{array}{l}\text { Extremely variable, sessile, } \\
\text { pedunculated }\end{array}$ & $1-6$ & $0.25-1.5 \mu \mathrm{m}$ & ND \\
\hline Powars et al. (1964) [12] & 1 & D group & Hook-like & $\mathrm{ND}$ & $<2.0 \mu \mathrm{m}$ & $63 \%$ \\
\hline $\begin{array}{l}\text { Lutzner and Hecht } \\
\text { (1966) [10] }\end{array}$ & 11 & $\begin{array}{l}\text { D group (10) } \\
\text { C group (1) }\end{array}$ & $\begin{array}{l}\text { Varied greatly in size and } \\
\text { shape, tags, threads, clubs, } \\
\text { drumstick-like }\end{array}$ & $1-10$ & $\mathrm{ND}$ & $60-80 \%$ \\
\hline Walzer et al. (1966) [11] & 11 & D group & $\begin{array}{l}\text { Variable, spherical, ovoid or } \\
\text { club shaped }\end{array}$ & $1-4$ & $0.5-1.5 \mu \mathrm{m}$ & $15-52 \%$; Ave. $=26 \%$ \\
\hline $\begin{array}{l}\text { Dallapiccola et al. (1984) } \\
\text { [14] }\end{array}$ & 1 & Mosaic 14 & Sessile, pedunculated & $3-6$ & $0.25-1.5 \mu \mathrm{m}$ & $40 \%$ \\
\hline Salama et al. (2004) [13] & 1 & 13 & Thread-like & $>2$ & ND & $80 \%$ \\
\hline
\end{tabular}

(Ave.: average; ND: not determined).

provide additional support to a clinician's suspicion of T18 and may aid in decisions of future testing and care for these complex cases.

Finally, it should be noted that our morphologic observations and conclusions are based on a single case. Further examination and careful review of peripheral blood smears from a larger cohort of T18 patients will be helpful in further validation prior to fully incorporating this observation into the diagnostic process.

\section{Conflict of Interests}

The authors declare that there is no conflict of interests regarding the publication of this paper.

\section{Authors' Contribution}

Basil M. Kahwash and Nicholas B. Nowacki contributed equally to the paper.

\section{Acknowledgment}

The authors thank Maria Nunez for her help in preparing this paper.

\section{References}

[1] A. Cereda and J. C. Carey, “The trisomy 18 syndrome," Orphanet Journal of Rare Diseases, vol. 7, article 81, 2012.

[2] S. Root and J. C. Carey, "Survival in trisomy 18," American Journal of Medical Genetics, vol. 49, no. 2, pp. 170-174, 1994.

[3] K. O. Kagan, D. Wright, C. Valencia, N. Maiz, and K. H. Nicolaides, "Screening for trisomies 21, 18 and 13 by maternal age, fetal nuchal translucency, fetal heart rate, free $\beta$-hCG and pregnancy-associated plasma protein-A," Human Reproduction, vol. 23, no. 9, pp. 1968-1975, 2008.

[4] M. L. Barr and E. G. Bertram, "A morphological distinction between neurones of the male and female, and the behaviour of the nucleolar satellite during accelerated nucleoprotein synthesis," Nature, vol. 163, no. 4148, pp. 676-677, 1949.
[5] S. Ohno and T. S. Hauschka, "Allocycly of the X-chromosome in tumors and normal tissues," Cancer Research, vol. 20, pp. 541$545,1960$.

[6] W. M. Davidson and D. R. Smith, "A morphological sex difference in the polymorphonuclear neutrophil leucocytes," British Medical Journal, vol. 2, no. 4878, pp. 6-7, 1954.

[7] H. A. Gardner, "The buccal smear: reassessment of its usefulness," Canadian Medical Association Journal, vol. 114, no. 6, pp. 527-530, 1976.

[8] M. L. Barr and E. R. Plunkett, “Testicular dysgenesis affecting the seminiferous tubules principally, with chromatin-positive nuclei," The Lancet, vol. 271, no. 6948, pp. 853-856, 1956.

[9] E. R. Huehns, M. Lutzner, and F. Hecht, "Nuclear abnormalities of the neutrophils in $\mathrm{D}_{1}$ (13-15)-trisomy syndrome," The Lancet, vol. 283, no. 7333, pp. 589-590, 1964.

[10] M. A. Lutzner and F. Hecht, "Nuclear anomalies of the neutrophil in a chromosomal triplication: the D1 (13-15) trisomy syndrome. An electron microscopic study." Laboratory Investigation, vol. 15, no. 3, pp. 597-605, 1966.

[11] S. Walzer, P. S. Gerald, G. Breau, D. O’Neill, and L. K. Diamond, "Hematologic changes in the D1 trisomy syndrome," Pediatrics, vol. 38, no. 3, pp. 419-429, 1966.

[12] D. Powars, R. Rohde, and D. Graves, "Foetal haemoglobin and neutrophil anomaly in the $\mathrm{D}_{1}$-trisomy syndrome," The Lancet, vol. 283, no. 7347, pp. 1363-1364, 1964.

[13] M. E. Salama, V. Shah, R. R. Lebel, and D. L. VanDyke, "Aberrant nuclear projections of neutrophils in trisomy 13," Archives of Pathology and Laboratory Medicine, vol. 128, no. 2, pp. 243-244, 2004.

[14] B. Dallapiccola, G. Ferranti, A. Giannotti, G. Novelli, L. Pasquini, and B. Porfirio, "A live infant with trisomy 14 mosaicism and nuclear abnormalities of the neutrophils," Journal of Medical Genetics, vol. 21, no. 6, pp. 467-470, 1984.

[15] K. Mehes, "Nuclear projections in neutrophils," Blood, vol. 28, no. 4, pp. 598-601, 1966. 


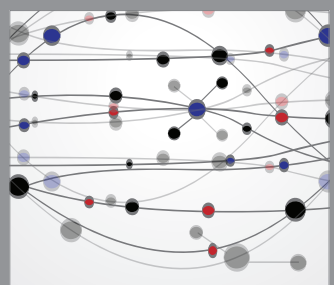

The Scientific World Journal
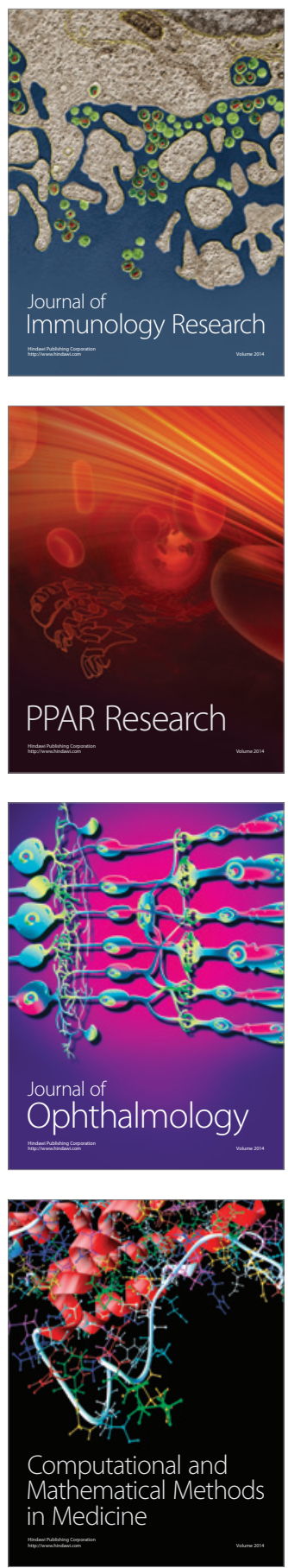

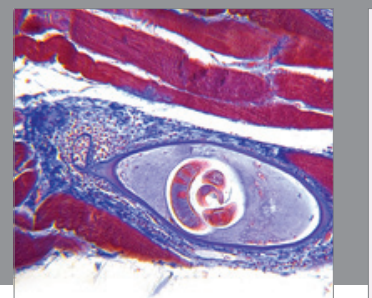

Gastroenterology

Research and Practice
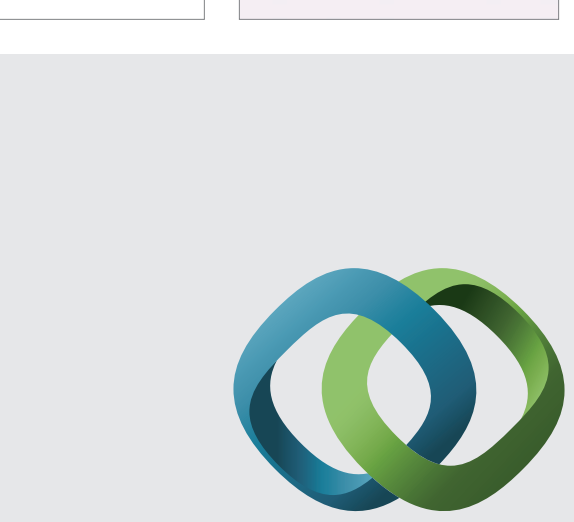

\section{Hindawi}

Submit your manuscripts at

http://www.hindawi.com
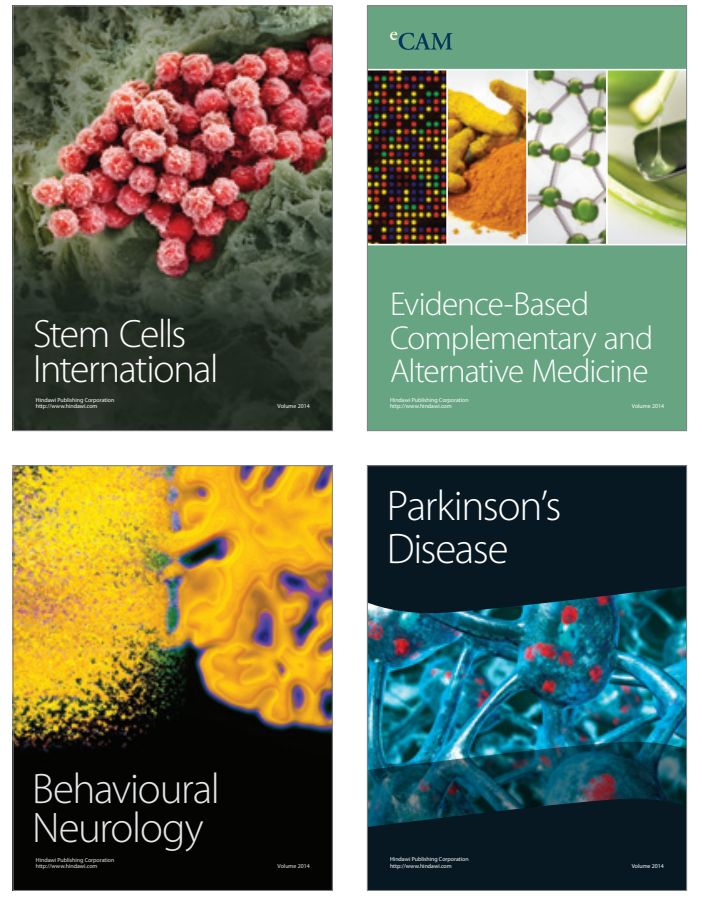
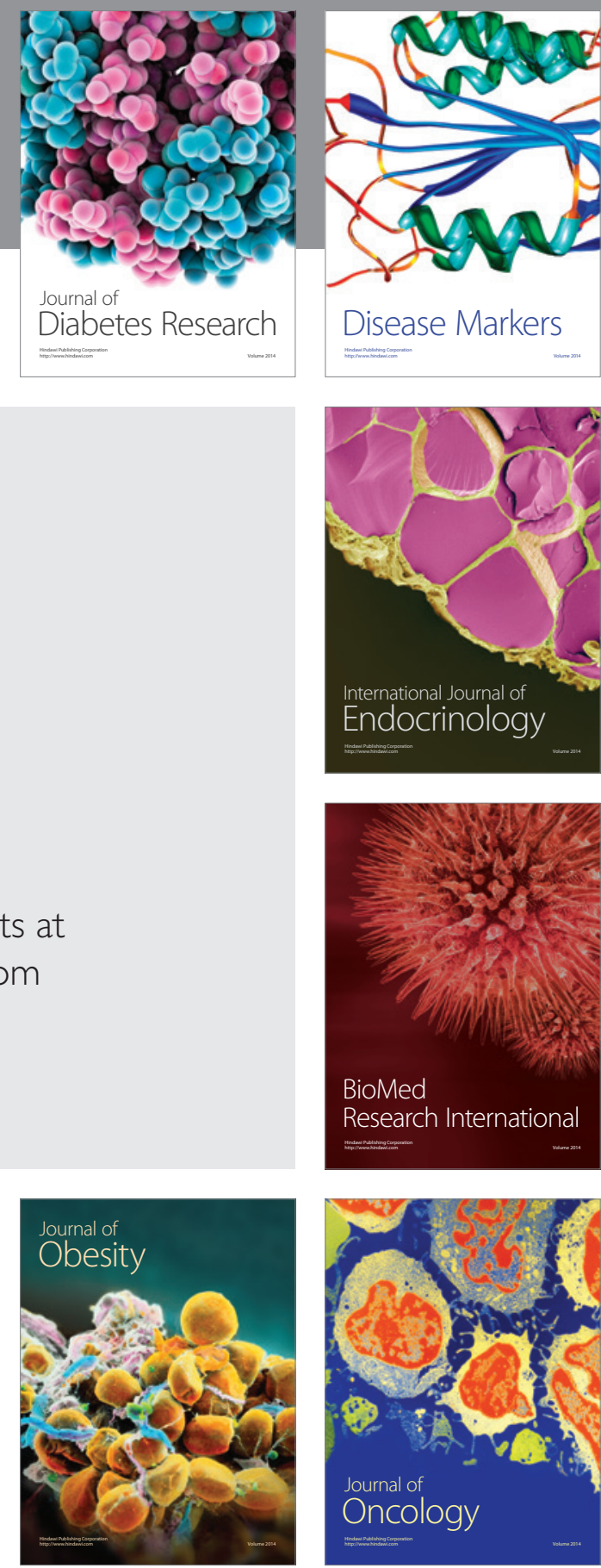

Disease Markers
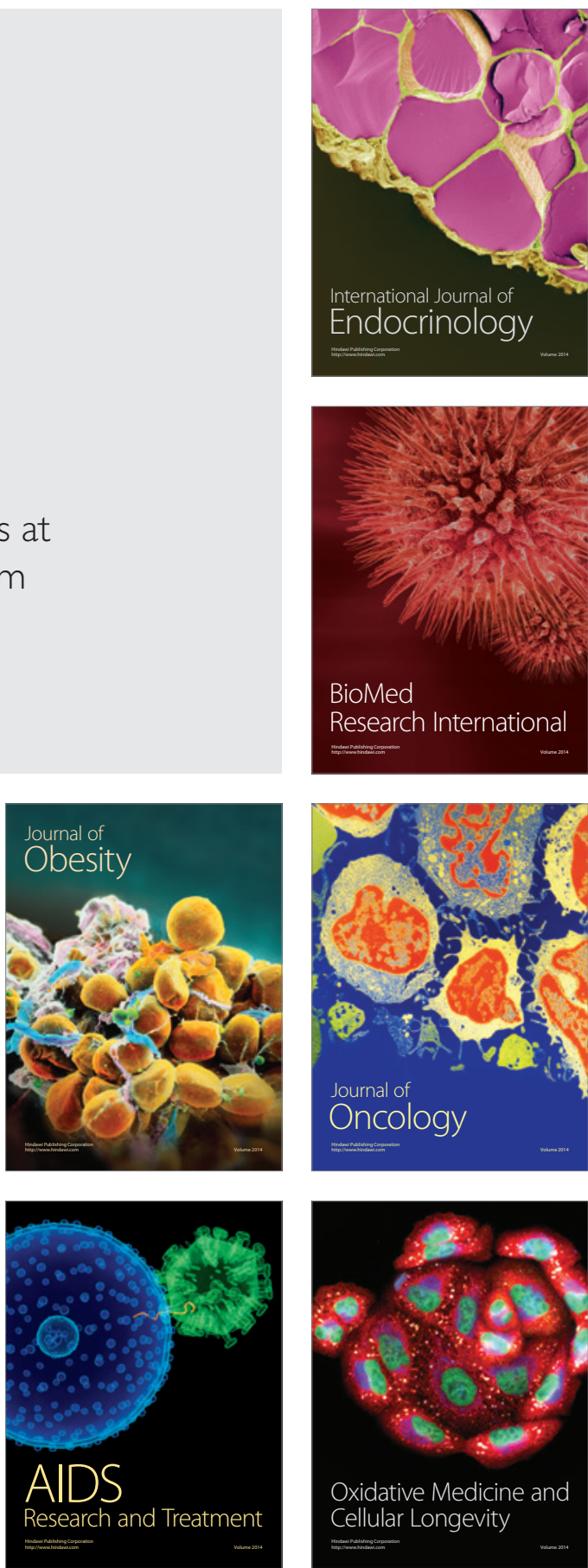